\title{
Avaliação do risco da arrecadação federal por meio de macrocarteiras de tributos
}

\author{
Fábio Daros de Freitas \\ Receita Federal do Brasil
}

Christóvão Thiago de Brito Neto

Receita Federal do Brasil

Alberto Ferreira de Souza

Universidade Federal do Espírito Santo

\begin{abstract}
Este artigo emprega o modelo média-variância de Harry Markowitz na formação de macrocarteiras de tributos com participações ótimas de agregados tributários na arrecadação federal. Essas macrocarteiras ótimas, ou macrocarteiras eficientes, são aquelas que produzem a menor instabilidade do crescimento da arrecadação para uma determinada taxa de crescimento esperada, ou uma maior taxa de crescimento esperada para uma determinada instabilidade aceitável da arrecadação. Avaliamos o efeito das participações ótimas propostas pelo nosso modelo para a arrecadação das receitas de um conjunto de agregados tributários e comparamos seu perfil de crescimento com os resultados obtidos pelo governo federal. Nossos resultados experimentais mostraram que, no contexto analisado, a estrutura tributária da arrecadação federal opera em um nível subótimo de instabilidade-crescimento. Através da diversificação eficiente das receitas dos agregados tributários foi possível obter, no perfil conservador, um crescimento acumulado de arrecadação 28 pontos percentuais acima do crescimento acumulado realizado dos mesmos agregados tributários e com apenas $25 \%$ da sua instabilidade - um risco quatro vezes menor. No perfil moderado, foi alcançado um crescimento acumulado 33 pontos percentuais acima, para o mesmo nível de instabilidade.
\end{abstract}

Palavras-chave: risco da arrecadação; planejamento de políticas fiscais; otimização de carteiras.

\section{Evaluation Brazilian federal revenue risk with tax macro portfolios}

This article employs Harry Markowitz's mean-variance model in the formation of macro portfolios of taxes with optimal participation of tax aggregates in federal revenue. These optimal macro portfolios, or efficient macro portfolios, are those that produce the lower revenue growth instability for a given expected growth rate, or the higher expected growth rate for a given acceptable growth instability. We evaluated the effects of the optimal participation proposed by our model for the revenue of a set of tax

Artigo recebido em jul. 2010 e aceito em maio 2011. 
aggregates and compared its growth profile with that achieved by the federal government. Our experimental results showed that, in the context examined, the Brazilian federal tax structure operates in a suboptimal level of instability-growth. Through the efficient diversification of tax aggregates revenues, it was possible to achieve, for the conservative profile, a cumulative revenue growth 28 percentage points higher than the realized cumulative revenue growth achieved with the same tax aggregates and with only $25 \%$ of its instability - a risk four times smaller. In moderate profile, we achieved a cumulative revenue growth 33 percentage points higher with the same level of instability.

KEY WORDS: revenue risk; fiscal policy planning; portfolio optimization.

\section{Introdução}

O Estado brasileiro tem seus objetivos fundamentais determinados no art. 3 o da Constituição Federal de 1988 - CF/88 (Brasil, 2007), entre os quais estão incluídos a garantia do desenvolvimento nacional e a redução das desigualdades sociais e regionais. Para perseguir esses objetivos, os governos têm de realizar um conjunto de despesas que tipicamente são custeadas pela arrecadação de tributos, conforme autorizado pela CF/88 no art. 145. Nos organismos estatais, especialmente nas administrações tributárias das três esferas de governo, a previsão de receitas públicas e a efetiva arrecadação de todos os tributos de sua competência constitucional são atribuições determinadas pelo art. 11 da Lei Complementar no 101, de 4 de maio de 2000, a Lei de Responsabilidade Fiscal. Dessa forma, a elaboração e a implantação de políticas fiscais efetivas que propiciem um crescimento estável e previsível da arrecadação são de interesse primordial das administrações públicas (Thompson e Gates, 2007).

A "demanda agregada" é a soma das despesas da sociedade com bens e serviços, cujos principais componentes, segundo Keynes (1936), são os gastos em consumo pessoal, a demanda por investimentos, os gastos governamentais em bens e serviços e as exportações líquidas. O governo pode afetar a demanda agregada com o uso das chamadas "políticas fiscais". As políticas fiscais podem ser orientadas às variações nos gastos governamentais, quando são denominadas "políticas orçamentárias", ou orientadas às variações nas receitas tributárias, chamadas "políticas tributárias".

Ao utilizar políticas orçamentárias, um aumento nos gastos governamentais é somado verticalmente à demanda por bens e serviços de consumo e de investimento, o que, em função do "efeito multiplicador", pode gerar um aumento ainda maior no produto nacional (Keynes, 1937; 1992). Para que ocorra o pleno impacto do efeito multiplicador no produto nacional, é necessário que a carga tributária não seja aumentada para pagar o gasto governamental adicional. Esse gasto deve ser financiado pelo aumento da dívida pública através de empréstimos no mercado financeiro (Wonnacott e Wonnacott, 1982).

Ao utilizar políticas tributárias, a demanda agregada será afetada de forma indireta, através do consumo. Quanto maior a carga tributária, menor é a renda pessoal disponível, e as variações nesta afetam o consumo. Um aumento da taxação na fonte do gasto é apropriado para o caso de alta demanda agregada e trajetória ascendente dos preços (Ocampo, 2002). Esse aumento diminuirá a renda disponível e, consequentemente, o consumo. Por outro lado, 
uma redução da taxação é adequada quando a demanda agregada está baixa e os preços estão em queda. Essa redução elevará a renda disponível e, por conseguinte, o consumo. O ajuste da carga tributária como política fiscal apresenta vantagens em relação às alterações nos gastos governamentais, uma vez que ele é menos controverso, mais rápido e mais ajustável de acordo com a atividade econômica.

A "volatilidade"1 macroeconômica tem altos custos econômicos e sociais, e os governos, em especial aqueles dos países em desenvolvimento, devem se concentrar na prevenção de crises domésticas decorrentes da gestão inadequada dos ciclos de crescimento econômico através de mecanismos que evitem os efeitos pró-cíclicos das políticas fiscais (Ocampo, 2002). As receitas tributárias são, em sua maior parte, alavancadas pelo crescimento econômico, e a imprevisibilidade e volatilidade (incerteza) de seu crescimento estimulam reações indesejáveis dos governos, que tipicamente oscilam entre padrões de aumento de gastos e de taxação. Um crescimento previsível e estável da arrecadação, com o menor grau de incerteza possível, ou menor grau de "instabilidade" ou "risco", é uma meta a ser perseguida pelas administrações públicas (Thompson e Gates, 2007). Nesse contexto, o risco pode ser interpretado como um evento ou condição incerta que, se ocorrer, terá um efeito positivo ou negativo sobre pelo menos um objetivo da administração (Dumont, Ribeiro e Rodrigues, 2006:125). A diversificação das fontes de receita é uma forma de atingir um crescimento estável da arrecadação, e a literatura recente mostra que a efetividade dessa diversificação depende mais dos comovimentos (covariâncias) das séries históricas das receitas do que do número de tributos utilizados (Thompson e Gates, 2007).

Fox (2003) analisou a crise fiscal dos estados dos EUA no início dos anos 2000 e destacou que os três maiores tributos estaduais arrecadaram menos em 2002 do que em 2001, fazendo com que a relação entre a arrecadação estadual e a renda das pessoas físicas fosse a menor dos 15 anos anteriores, apresentando uma queda de 6,4\% em relação a 2001. Fox apontou a estrutura tributária como uma das causas desse dilema fiscal, destacando a volatilidade das receitas estaduais como uma de suas três principais características impactantes.

Ocampo (2002) estudou a macroeconomia dos ciclos de expansão e contração em economias emergentes, com foco no papel das políticas domésticas de países em desenvolvimento na administração de ciclos de expansão e contração externamente gerados. Ele destacou que a volatilidade macroeconômica tem altos custos econômicos e sociais, e que crises domésticas severas podem gerar perdas equivalentes a grandes proporções do Produto Interno Bruto (PIB) desses países. Portanto, as autoridades desses países precisam focar sua atenção na prevenção de crises através da gestão da expansão econômica, uma vez que as crises são resultados inevitáveis de expansões econômicas mal geridas. Ocampo apontou ainda que, no conjunto de políticas anticíclicas, as políticas fiscais constituem um dispositivo anticíclico

\footnotetext{
${ }^{1}$ Os termos "volatilidade" e "risco" são costumeiramente utilizados de forma indistinta na área de finanças e expressos pela variabilidade de uma grandeza econômica modelada como uma variável aleatória. Tipicamente, esta variabilidade é medida pela variância da série histórica das observações dessa variável aleatória e interpretada como medida de incerteza da ocorrência de seu valor esperado no futuro.
} 
bastante útil, e mecanismos de esterilização temporária das receitas do setor público através de fundos de estabilização ou da adoção de alíquotas flexíveis para o controle da expansão dos gastos privados podem ser um importante complemento a essas políticas, possibilitando maximizar a arrecadação nesse contexto.

A Moderna Teoria de Carteiras oferece um conjunto de métodos quantitativos através dos quais o investidor racional pode otimizar a diversificação de seus investimentos. Sua origem se confunde com a proposição do modelo média-variância por Harry Markowitz em 1952 (Markowitz, 1952). Fundamentalmente, o modelo média-variância reduz a variabilidade do comportamento de um agregado financeiro - a carteira de investimentos —, minimizando a sua variância através da escolha ótima dos pesos, ou "participações", de cada componente no agregado. A variância da carteira é utilizada como medida de seu risco total, e a contribuição de risco individual de cada componente da carteira, dado por suas variâncias individuais, pode ser totalmente eliminada, fazendo com que o risco total seja dado apenas pelo efeito dos comovimentos dos componentes da carteira, medido pelas suas covariâncias (Elton et al., 2007).

A notória correção do modelo média-variância ao capturar as relações de interdependência de cada ativo com todos os demais resulta em um custo computacional quadrático em relação ao número de ativos. Isto foi um dos principais impedimentos para sua pronta adoção em larga escala pelo mercado, e teve como consequência o surgimento de aproximações e simplificações do modelo original, bem como o desenvolvimento de métodos computacionais mais eficientes (Sharpe, 1963, 1971; Konno, 1990; Konno e Yamazaki, 1991; Konno e Suzuki, 1992; Konno, Pliska e Suzuki, 1993; Konno, Shirakawa e Yamazaki, 1993).

Recentemente, o significativo aumento do poder computacional e da capacidade de armazenamento dos computadores, bem como o surgimento de paradigmas de computação paralela de baixo custo (De Souza e Freitas, 1995), estabeleceram um ambiente propício para se reexaminar a plena aplicabilidade do arcabouço média-variância em problemas do mundo real. Se outrora a aplicação prática do modelo média-variância era considerada de alto custo (Vasarhelyi, 1976), o cenário atual sugere não apenas sua aplicação em problemas do porte demandado pelo mercado financeiro, mas também sua exploração em outros domínios de aplicação.

Silva (1996) aplicou o modelo média-variância à administração da dívida pública brasileira, buscando estratégias ótimas para seu financiamento. Segundo Silva, como a captação de recursos pode ser realizada por meio de diversas alternativas, combinações ótimas dessas alternativas podem formar carteiras de passivos adequadas, que forneçam o menor custo (menor retorno, na visão do credor) para um determinado nível de risco, diminuindo significativamente as incertezas associadas ao devedor. O conjunto dessas carteiras ótimas forma a "fronteira eficiente de financiamento", que contempla todas as combinações ótimas de financiamento disponíveis. O modelo foi aplicado à administração da Dívida Pública Mobiliária Federal interna (DPMFi), utilizando retornos e riscos estimados por meio de cenários. Seus resultados de simulação produziram três carteiras ótimas que alcançaram maior ganho potencial (menor custo efetivo esperado) e menor dispersão (desvio-padrão) do que a carteira praticada pelo Tesouro, projetando uma economia de até R $\$$ 103 milhões à época. 
Thompson e Gates (2007) apresentaram um artigo de revisão que propôs a utilização de um conjunto de ferramentas da moderna teoria de finanças no planejamento da gestão das receitas públicas. Segundo Thompson e Gates, uma das principais metas das administrações públicas é propiciar um crescimento estável e previsível da arrecadação, com o menor grau de incerteza possível. Nesse ponto, eles destacam que a diversificação das fontes de receita é uma forma de atingir essa meta e que a efetividade dessa diversificação depende mais do comportamento conjunto dos desempenhos dos tributos, seus comovimentos, do que simplesmente do número de tipos de tributos utilizados. Para tal, eles propõem, entre outras técnicas, o emprego de métodos de previsão de séries temporais na análise do crescimento da arrecadação e do modelo média-variância na gestão de sua volatilidade. Apesar de ressaltar que a volatilidade não pode ser totalmente eliminada por conta da ausência de correlações negativas suficientes entre os tributos (as receitas dos estados dos EUA apresentavam coeficiente de correlação de 0,65 em média), Thompson e Gates comentam que a parcela não sistemática da volatilidade pode ser completamente eliminada.

Gentry e Ladd (1994) empregaram um modelo de seleção de carteiras para avaliar como a natureza dos tributos e a economia dos estados afetam as escolhas de gestão disponíveis às autoridades estatais, examinando o caso dos estados de North Carolina e Massachusetts nos EUA. Segundo Gentry e Ladd, os economistas devotam bastante atenção às características individuais dos tributos, mas pouca atenção à questão mais ampla acerca da especificação do conjunto de tributos mais adequado a cada jurisdição governamental. O modelo de seleção de carteiras desenvolvido forneceu as participações ótimas em um conjunto de tributos equivalentes para os dois estados, produzindo uma fronteira eficiente de crescimento-instabilidade que levou em consideração as expectativas de crescimento e instabilidade de cada tributo e também um conjunto de restrições de progressividade e competitividade entre os estados. Seus resultados evidenciaram a grande diferença da progressividade da estrutura tributária dos dois estados e a dominância do imposto sobre a renda nas carteiras ótimas para uma grande faixa de crescimentos esperados das fronteiras eficientes. As diferenças encontradas nas fronteiras eficientes dos dois estados sugeriram recomendações de políticas tributárias específicas para cada um, contrariando a prescrição da Comissão Consultiva de Relações Intergovernamentais dos EUA (Advisory Commission on Intergovernmental Relations - ACIR) para a adoção de estruturas tributárias idênticas para os estados.

Este artigo trata o conjunto de tributos de competência da União como um universo de "ativos de risco", ${ }^{2}$ com os quais podemos formar "carteiras de tributos" à luz da Moderna Teoria de Carteiras (Elton et al., 2007; Sharpe, Alexander e Bailey, 1999). Para tal, a relação entre a instabilidade e o crescimento das receitas individuais dos tributos é tratada como a relação entre o risco e o retorno de ativos, a partir da qual podemos desenvolver medidas para a ins-

\footnotetext{
${ }^{2}$ Ativos de risco são aqueles instrumentos de investimento cujo retorno esperado é incerto e para os quais podemos derivar uma medida quantitativa dessa incerteza, ou "risco". Ativos com retorno esperado certo ou risco muito próximo de zero são denominados "ativos sem risco".
} 
tabilidade e o crescimento da receita de agregados da arrecadação federal de forma similar ao risco e ao retorno de carteiras de investimentos (Gentry e Ladd, 1994). Empregamos o modelo média-variância de Harry Markowitz $(1952,1991)$ para obter participações ótimas de tributos na arrecadação federal, ou "carteiras eficientes de tributos", que são aquelas que produzem a menor instabilidade da arrecadação para um determinado crescimento esperado, ou um maior crescimento esperado para uma determinada instabilidade aceitável da arrecadação.

Os modelos propostos neste artigo foram avaliados através de um conjunto de experimentos de simulação que comparou os perfis de crescimento das carteiras eficientes de tributos com o crescimento da arrecadação federal realizada. Nossos resultados mostraram que através da diversificação eficiente das participações das receitas tributárias no agregado da arrecadação federal é possível mitigar parte considerável da instabilidade (risco) da arrecadação. Em um dos cenários avaliados, obtivemos um crescimento acumulado de arrecadação da ordem de 28 pontos percentuais acima do crescimento do agregado da arrecadação federal, com apenas $25 \%$ de sua instabilidade - uma volatilidade quatro vezes menor. Em outro cenário, foi alcançado um crescimento acumulado da ordem de 33 pontos percentuais acima do crescimento do agregado da arrecadação federal para o mesmo nível de instabilidade. $\mathrm{Na}$ comparação com o resultado das Receitas Administradas pela Receita Federal do Brasil, as carteiras de tributos alcançaram um crescimento acumulado superior da ordem de 34 pontos percentuais, com apenas $25 \%$ de sua instabilidade, e, em outro cenário comparado, alcançaram um crescimento superior da ordem de 39 pontos percentuais, exibindo os mesmos níveis de instabilidade.

Este artigo está organizado como a seguir. Após esta introdução, na seção 2 apresentaremos as noções fundamentais relacionadas aos modelos desenvolvidos, bem como nossa estratégia para a aplicação do modelo média-variância na diversificação da arrecadação federal. Na seção 3, apresentaremos os dados, a metodologia e as métricas de avaliação utilizadas em nossos experimentos de simulação. Nossos resultados experimentais serão apresentados na seção 4, e encerraremos este artigo discutindo seus resultados na seção 5 e apresentando nossas conclusões e perspectivas na seção 6 .

\section{Noções fundamentais}

Esta seção apresenta as noções fundamentais relacionadas aos temas abordados neste artigo. Primeiro, faremos um resumo dos tributos de competência da União, que são foco deste artigo, e em seguida será apresentada a modelagem proposta para a diversificação da arrecadação com o modelo média-variância de Harry Markowitz, com a qual podemos formar carteiras ótimas de tributos à luz da Moderna Teoria de Carteiras.

\subsection{Tributos de competência da união}

O Código Tributário Nacional (CTN), instituído pela Lei no 5.172, de 25 de outubro de 1966, oferece-nos um conjunto de definições tributárias relevantes para os objetivos deste artigo. 
Nos termos do art. 3ํ do CTN, "tributo é toda prestação pecuniária compulsória, em moeda ou cujo valor nela se possa exprimir, que não constitua sanção de ato ilícito, instituída em lei e cobrada mediante atividade administrativa plenamente vinculada". Os tributos estão divididos em (i) impostos, (ii) taxas, (iii) contribuições de melhoria e (iv) contribuições especiais; estas últimas determinadas pela CF/88 nos arts. 149 e 195.

Os tributos de interesse deste artigo são aqueles de competência da União. O art. 16 do CTN dispõe que "imposto é o tributo cuja obrigação tem por fato gerador uma situação independente de qualquer atividade estatal específica, relativa ao contribuinte". Os impostos integrantes do Sistema Tributário Nacional estão dispostos no título 3 do CTN, o qual é composto por quatro capítulos: o capítulo 1 apresenta suas disposições gerais, o capítulo 2 trata dos impostos sobre o comércio exterior, o capítulo 3 trata dos impostos sobre o patrimônio e a renda, e o capítulo 4 trata dos impostos sobre a produção e a circulação.

O capítulo 2 do CTN apresenta dois impostos: o Imposto sobre a Importação (II) e o Imposto sobre a Exportação (IE). A base econômica do Imposto sobre a Importação é a entrada no território nacional, para incorporação à economia interna, de bem destinado ou não ao comércio, produzido fora do território nacional pela natureza ou pela ação humana (Paulsen, 2009:12). O Imposto sobre a Importação está intrinsecamente ligado às políticas cambial e de comércio exterior, nos termos do art. 21 do CTN. A base econômica do Imposto sobre a Exportação é a saída do território nacional, para incorporação a outra economia, de bem destinado ou não ao comércio, produzido dentro do território nacional pela natureza ou pela ação humana, ou ainda os produtos nacionalizados. O Imposto sobre a Exportação, assim como o Imposto sobre a Importação, também está intrinsecamente ligado às políticas cambial e de comércio exterior, nos termos do art. 26 do CTN.

O capítulo 3 do CTN possui dois impostos: o Imposto sobre a Propriedade Territorial Rural (ITR) e o Imposto sobre a Renda e Proventos (IR). A base econômica do Imposto sobre a Propriedade Territorial Rural é a propriedade, o domínio útil ou a posse de imóvel por natureza localizado fora da zona urbana dos municípios. A base econômica do Imposto sobre a Renda e Proventos são a "renda" e os "proventos" recebidos — a jurisprudência pacifica a "renda" como o acréscimo patrimonial produto do capital, do trabalho ou da combinação de ambos, e os "proventos" como o acréscimo patrimonial não compreendido no conceito de renda.

O capítulo 4 do CTN possui dois impostos: o Imposto sobre Produtos Industrializados (IPI) e o Imposto sobre Operações de Crédito, Câmbio e Seguro, e sobre Operações relativas a Títulos e Valores Mobiliários (IOF). A base econômica do Imposto sobre Produtos Industrializados é a submissão do produto a qualquer operação que lhe modifique a natureza ou a finalidade, ou o aperfeiçoe para o consumo. Ainda, o IPI incide sobre os bens de procedência estrangeira e sobre aqueles abandonados ou apreendidos e levados a leilão. A base econômica do IOF é separada em função da operação, sendo: 
จ para as operações de crédito, a disponibilização econômica ou jurídica do montante total ou parcial ao interessado;

จ para as operações de câmbio, a disponibilização econômica ou jurídica do montante total ou parcial de moeda nacional ou estrangeira ao interessado;

、 para as operações de seguro, a emissão da apólice ou recebimento do prêmio;

จ para as operações relativas aos valores mobiliários, a emissão, transmissão, pagamento ou resgate dos mesmos.

As "contribuições especiais"3 são determinadas na CF/88 através do art. 149, que dispõe da competência da União para instituir contribuições sociais, de intervenção no domínio econômico e de interesse das categorias profissionais ou econômicas; e através do art. 195, que dispõe que a seguridade social também será financiada pelas contribuições sociais incidentes sobre a folha de salários, a receita ou faturamento, o lucro, a receita de concursos de prognósticos e sobre o valor das importações de bens ou serviços. A base econômica das contribuições sociais é separada em função da incidência. Empregar funcionários, vender produtos ou serviços e gerar lucros são bases de incidência para as contribuições sociais. A Contribuição para Financiamento da Seguridade Social (Cofins), a Contribuição para o Programa de Integração Social/Programa de Formação do Patrimônio do Servidor Público (PIS/Pasep) e a Contribuição Social sobre o Lucro Líquido (CSLL) são exemplos de contribuições especiais com incidência sobre o faturamento das empresas.

\subsection{Moderna Teoria de Carteiras na diversificação da arrecadação}

O total das receitas arrecadadas de um conjunto de tributos, ou a sua "arrecadação", está sujeito a flutuações decorrentes das atividades econômicas relacionadas à base econômica de cada tributo. Essas flutuações podem ocasionar determinados graus de instabilidade na arrecadação, aumentando seu risco e prejudicando suas estimativas de crescimento futuro. A diversificação das fontes de receita é uma forma de atingir um crescimento estável e previsível da arrecadação (Thompson e Gates, 2007).

Este artigo utiliza o modelo média-variância (Markowitz, 1952, 1991) como arcabouço para a diversificação eficiente da arrecadação, tratando um conjunto de tributos como um universo de ativos de risco e derivando uma fronteira eficiente para esse conjunto de tributos. Esta seção apresenta a modelagem empregada para a aplicação do modelo média-variância na diversificação eficiente da arrecadação.

\footnotetext{
${ }^{3}$ As contribuições especiais recebem este nome para diferenciá-las das contribuições de melhoria no âmbito da $\mathrm{CF} / 88$.
} 


\subsubsection{Crescimento das receitas tributárias}

Nossa abordagem para a diversificação eficiente da arrecadação com o modelo média-variância, tal como em sua aplicação clássica no mercado de ações, também é baseada em séries temporais, sendo descrita a seguir.

As diversas despesas que os governos têm de realizar no cumprimento de sua missão institucional tipicamente são custeadas pela arrecadação de tributos. Como em projetos de investimento, o volume financeiro total arrecadado por um tributo, ou sua "receita", é uma medida útil acerca de seu desempenho individual, mas torna-se sem utilidade na comparação entre os desempenhos de tributos que incidem sobre bases econômicas distintas. De forma similar ao retorno de investimentos, a "taxa de crescimento", ou simplesmente "crescimento", da receita de um determinado tributo é aqui definida como uma medida relativa que se propõe a quantificar a variação da receita arrecadada do tributo no horizonte de interesse, sendo dada por: ${ }^{4}$

$$
g_{t}=\frac{R_{t}-R_{t-1}}{R_{t-1}}, \quad t \geq 1
$$

onde $g_{t}$ é o crescimento de um período da receita proveniente da arrecadação do tributo no tempo $t$, e $R_{t}$ e $R_{t-1}$ são suas receitas nos tempos $t$ e $t_{t-1}$, respectivamente.

Os $N+1$ valores da receita arrecadada de um tributo e suas respectivas $N$ taxas de crescimento formam as séries históricas:

$$
\begin{gathered}
R^{\prime}=\left(R_{0}, R_{1} \ldots, R_{\mathrm{N}}\right) \mathrm{e} \\
g^{\prime}=\left(g_{1}, g_{2} \ldots, g_{\mathrm{N}}\right)
\end{gathered}
$$

As figuras 1 e 2 mostram dois exemplos típicos de séries de receitas e de crescimento das receitas de tributos de competência da União, quais sejam, a Contribuição Social sobre o Lucro Líquido (CSLL) e o Imposto sobre a Importação (II). A figura 1 mostra as séries das 161 observações mensais das receitas arrecadadas da CSLL e do II entre janeiro de 1996 e maio de 2009, em que podemos notar os perfis distintos de evolução de suas receitas; a figura 2 mostra as séries das 160 observações do crescimento mensal dessas receitas, calculado conforme a eq. 1 , entre fevereiro de 1996 e maio de 2009, em que podemos notar que a CSLL apresenta uma oscilação superior ao II.

\footnotetext{
${ }^{4}$ A definição da eq. 1 e as demais definições desta seção também são válidas para agregados tributários de qualquer natureza.
} 
Figura 1

Exemplos de séries históricas das receitas de tributos da União

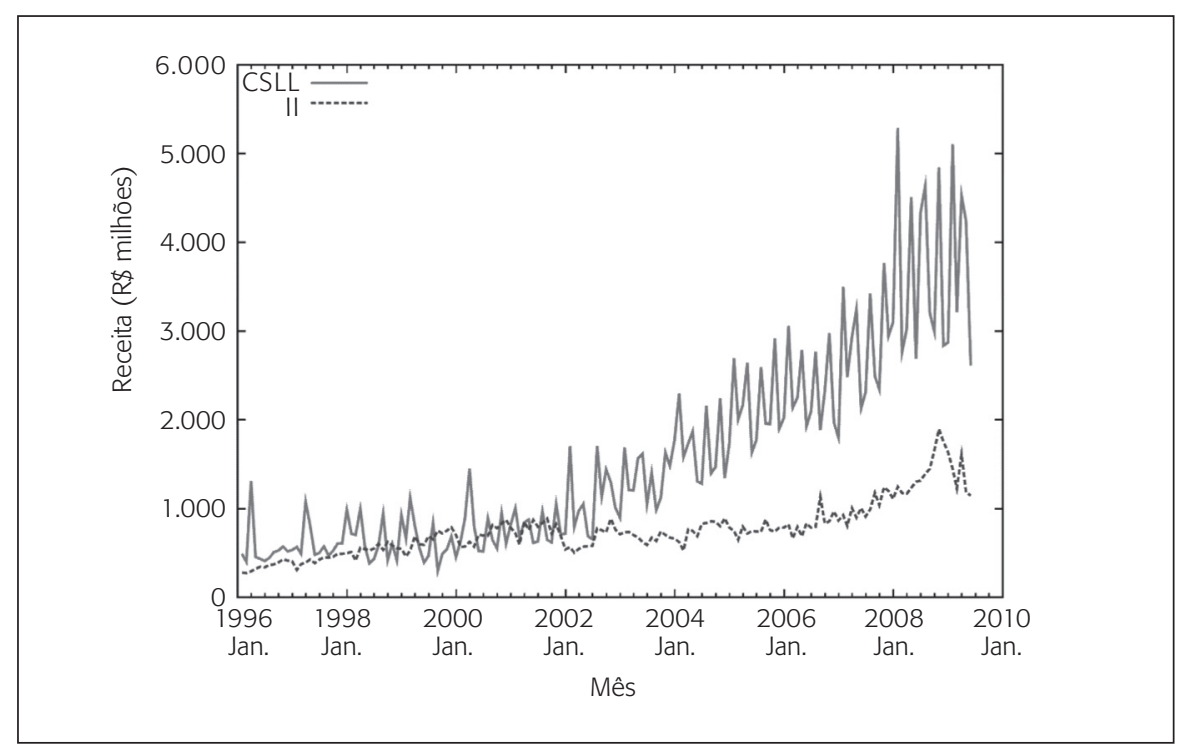

São mostradas as séries de 161 observações mensais das receitas da Contribuição Social sobre o Lucro Líquido (CSLL) e do Imposto sobre a Importação (II) entre janeiro de 1996 e maio de 2009, em que os perfis distintos de evolução de suas receitas são evidenciados.

Figura 2

Exemplos de séries históricas de crescimento das receitas de tributos da União

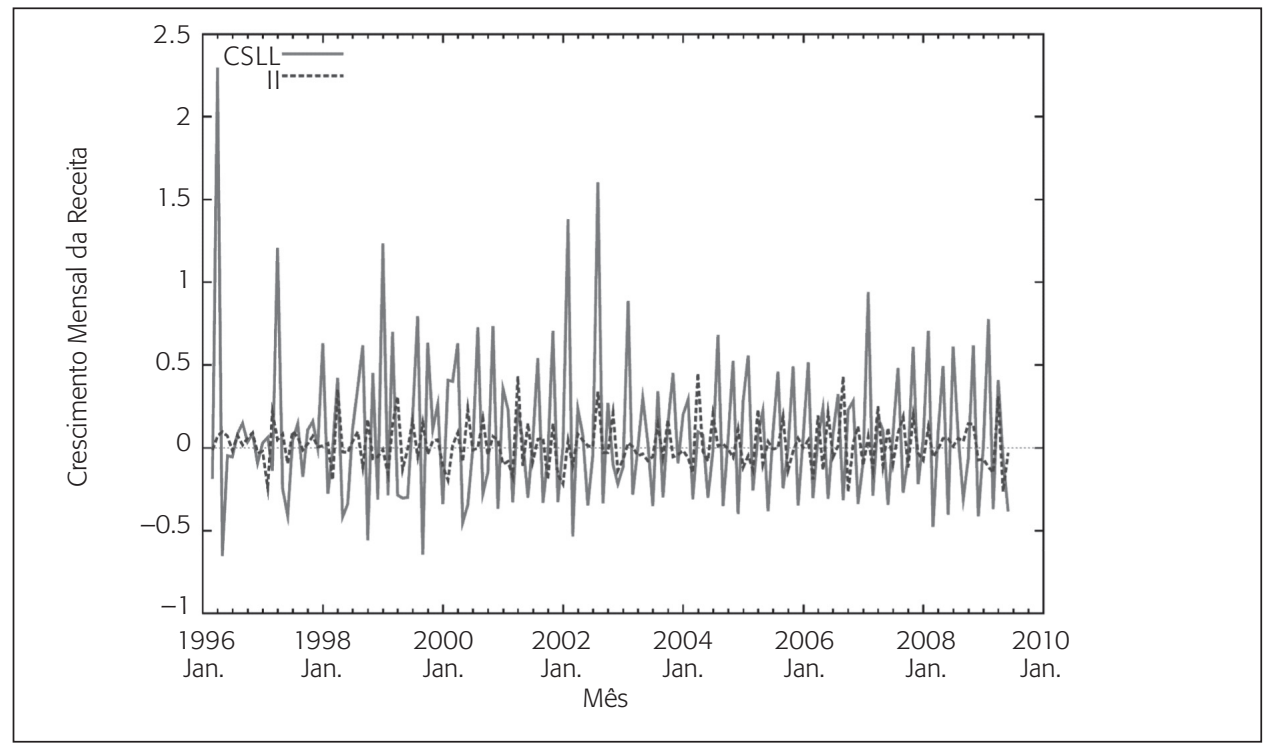

RAP - Rio de Janeiro 46(1):93-123, jan./fev. 2012 
São mostradas as séries de 160 observações do crescimento mensal das receitas da Contribuição Social sobre o Lucro Líquido (CSLL) e do Imposto sobre a Importação (II), calculadas entre fevereiro de 1996 e maio de 2009 a partir de suas respectivas receitas mensais. Os perfis distintos de oscilação das duas séries são evidenciados, onde a CSLL apresenta uma oscilação bastante superior ao II.

\subsubsection{Diversificação eficiente da arrecadação}

De forma similar às definições do modelo média-variância, apresentaremos nesta seção as medidas equivalentes ao retorno esperado e ao risco dos ativos de investimento para os tributos e a carteira de tributos, que no contexto da diversificação da arrecadação serão denominadas "crescimento esperado" e "instabilidade" da arrecadação (Gentry e Ladd, 1994).

\section{O MODELO MÉDIA-VARIÂNCIA APLICADO À DIVERSIFICAÇÃO DA ARRECADAÇÃO}

A razão percentual da receita de um determinado tributo pela receita total arrecadada de um conjunto de tributos que o inclui pode ser tratada como a participação desse tributo em uma carteira de tributos. Nessa aplicação do modelo média-variância, uma carteira será equivalente a um conjunto de $M$ tributos, cada qual com um respectivo peso, ou "participação", associado, cujo somatório de suas receitas individuais reflita a arrecadação total desse conjunto de tributos. Cada participação $X_{i}=1, \ldots, M$, com $0 \leq X_{i} \leq 1$ e $\Sigma_{i} X_{i}=1$, representa, portanto, a fração do valor da arrecadação total da carteira de tributos que é proveniente do tributo $i$. Dessa forma, o crescimento realizado da arrecadação total da carteira de tributos no tempo $t$, $g_{p t}$, é dado pela combinação linear das participações e dos crescimentos individuais das receitas de seus tributos componentes, ou seja:

$$
g_{p t}=\sum_{i=1}^{M} X_{i} g_{i t}
$$

onde $M$ é o número de tributos da carteira, $X_{i}$ é a participação do tributo $i$ na arrecadação total e $g_{i t}$ é o crescimento realizado da receita do tributo $i$ no tempo $t$.

O crescimento esperado da receita de um tributo é definido como:

$$
\bar{g}=\frac{1}{N} \sum_{t=1}^{N} g_{t}
$$

onde $g$ é o crescimento esperado da receita do tributo para o tempo $t=N+1, N$ é o tamanho da série histórica $g^{\prime}$ e $g_{t}$ é o crescimento da receita do tributo no tempo $t .^{5}$

\footnotetext{
${ }^{5}$ Gentry e Ladd (1994) definiram o crescimento da receita de um tributo a partir da regressão $d \log R_{t}=b+e_{t}$, onde $d \log R_{t}$ é a variação no logaritmo natural da receita real (deflacionada pelo deflator implícito de preços) entre os tempos $t$ e $t-1, b$ é a taxa de crescimento estimada e $e_{t}$ é um erro aleatório estacionário. Nossa definição de
} 
O crescimento esperado para a arrecadação da carteira de tributos, $\bar{g}_{p}$, é então definido pela combinação linear das participações e dos crescimentos esperados das receitas de seus tributos como:

$$
\bar{g}_{p}=\sum_{i=1}^{M} X_{i} \bar{g}_{i}
$$

onde $M$ é o número de tributos na carteira, $X_{i}$ é a participação do tributo $i$ na carteira e $\bar{g}_{i}$ é o crescimento esperado da receita do tributo $i$.

A instabilidade, ou risco, associada ao crescimento esperado da receita de um tributo é definida como a variância de sua série de crescimentos de receita como:

$$
\nu_{g}=\sigma_{g}^{2}=\frac{1}{N-1} \sum_{t=1}^{N}\left(g_{t}-\bar{g}\right)^{2}
$$

onde $v_{g}$ é a instabilidade associada ao crescimento esperado da receita do tributo para o tempo $t=N+1, N$ é o tamanho da série histórica $g^{\prime}, g_{t}$ é o crescimento realizado da receita do tributo no tempo $t$ e $\bar{g}$ é o crescimento de receita esperado para o tempo $t=N+1$. Assim como o risco associado ao retorno esperado de um ativo de investimento, a instabilidade associada ao crescimento esperado da receita do tributo busca refletir a incerteza da realização de seu crescimento esperado (eq. 5) - a ocorrência do crescimento esperado (valor médio) seria menos provável em séries com maior dispersão (maior instabilidade) do que em séries com menor dispersão (menor instabilidade).

A instabilidade da carteira de tributos é definida como a variância da combinação linear das participações dos tributos na carteira e de suas séries de crescimentos de receita, definida em termos da covariância entre cada par de tributos como:

$$
v_{p_{g}}=\sigma_{p_{g}}^{2}=\sum_{i=1}^{M} \sum_{j=1}^{M} X_{i} X_{j} \gamma_{g_{i j}}
$$

onde $v_{p g}$ é a instabilidade total da carteira, que é igual à variância $\sigma_{p g}^{2}$ da combinação linear das participações e das séries de crescimento dos tributos, $M$ é o número de tributos na carteira, $X_{i}$ e $X_{j}$ são as participações individuais dos tributos $i$ e $j$ na carteira, respectivamente, e $\gamma_{g i j}$ é a covariância dos crescimentos das receitas do par de tributos $i$ e $j$, que é definida como:

A eq. 8 pode ser reescrita como:

crescimento esperado da receita de um tributo (eq. 5) foi derivada no contexto do valor esperado de sua série de crescimentos, $g^{\prime}$. 


$$
\gamma_{g_{i j}}=\frac{1}{N-1} \sum_{t=1}^{N}\left(g_{i t}-\bar{g}_{i}\right)\left(g_{j_{t}}-\bar{g}_{j}\right)
$$

onde $N$ é o tamanho das séries históricas, $g_{i t}$ e $g_{j t}$ são os crescimentos de receita realizados dos tributos $i$ e $j$ no tempo $t$, e $\bar{g}_{i}$ e $\bar{g}_{j}$ são crescimentos de receita esperados dos tributos $i$ e $j$, respectivamente, para o tempo $t=N+1$.

A eq. 8 pode ser reescrita como:

$$
\begin{aligned}
v_{p_{g}}=\sigma_{p_{g}}^{2} & =\sum_{i=1}^{M} X_{i}^{2} \sigma_{g_{i}}^{2}+\sum_{i=1}^{M} \sum_{\substack{j=1 \\
j \neq i}}^{M} X_{i} X_{j} \gamma_{g_{i j}} \\
& =\sum_{i=1}^{M} X_{i}^{2} v_{g_{i}}+\sum_{i=1}^{M} \sum_{\substack{j=1 \\
j \neq i}}^{M} X_{i} X_{j} \gamma_{g_{i j}}
\end{aligned}
$$

onde $v_{p g}$ é a instabilidade total da carteira de tributos, $M$ é o número de tributos na carteira, $X_{t}$ e $X_{j}$ são as participações individuais dos tributos $i$ e $j$ na carteira, respectivamente, $v_{g i}\left(\sigma_{g i}^{2}\right)$ é a instabilidade individual (variância dos crescimentos) do tributo $i$ e $\gamma_{g i j}$ é a covariância das séries de crescimentos de receitas do par de tributos $i$ e $j$.

Uma aplicação do modelo média-variância para a diversificação da arrecadação pode então ser definida através do seguinte problema de programação quadrática:

Minimize $\quad v_{p_{g}}=\sum_{i=1}^{M} X_{i}^{2} \nu_{g_{i}}+\sum_{i=1}^{M} \sum_{\substack{j=1 \\ j \neq i}}^{M} X_{i} X_{j} \gamma_{g_{i j}}$

Sujeito a

$$
\begin{gathered}
\sum_{i=1}^{M} X_{i} \bar{g}_{i}=g_{d} \\
\sum_{i=1}^{M} X_{i}=1 \\
X_{i} \geq 0, \quad i=1, \cdots, M \\
l_{i} \leq X_{i} \leq u_{i} \quad i=1, \cdots, M .
\end{gathered}
$$


A eq. 11 é a função objetivo a ser minimizada, qual seja, a instabilidade da carteira de tributos, $v_{p g}$; a eq. 12 é a restrição que garante o crescimento de arrecadação desejado, $g_{d}$; a eq. 13 é a restrição que garante a integralidade da carteira com a alocação total das participações dos tributos e a eq. 14 restringe o modelo para participações positivas apenas. A eq. 15 é uma restrição adicional ao modelo média-variância original que impõe limites inferior $\left(l_{i}\right)$ e superior $\left(u_{i}\right)$ para a participação $X_{i}$ na carteira (Sharpe, 1987).

A extensão do modelo média-variância implementada através da inserção da eq. 15 no modelo original possibilita a elaboração de cenários e, consequentemente, a aplicação do modelo de forma mais adequada à diversificação da arrecadação.

\section{FRONTEIRA EFICIENTE INSTABILIDADE-CRESCIMENTO}

A "fronteira eficiente instabilidade-crescimento" (Gentry e Ladd, 1994) pode ser obtida por meio da resolução do problema de minimização definido pelas eqs. 11 a 15 para vários valores de crescimento de arrecadação desejado.

Em termos de composição de carteiras de tributos, a diversificação da instabilidade da arrecadação também é conseguida a partir da seleção de pares de tributos com coeficientes de correlação negativos ou nulos. Ou seja, selecionando-se tributos (isto é, atribuindo participações de tributos na carteira) que apresentem movimentos de crescimento de receita em direções opostas ao longo do tempo, exibindo assim um efeito de compensação de quedas e de suavização de crescimentos acentuados das receitas.

\section{MACROCARTEIRAS DE TRIBUTOS}

É possível empregar uma abordagem de macroativos para a diversificação da arrecadação através da utilização de agregados tributários, formando as "macrocarteiras de tributos". As características dessa abordagem são as mesmas das macrocarteiras de investimentos, em que se destacam a maior eficiência da alocação dos ativos (Brito Neto, 1989).

\section{Métodos}

Neste artigo, analisamos a composição da arrecadação de um conjunto de tributos de competência da União e a comparamos com composições ótimas obtidas através do modelo média-variância. Para tal, desenhamos um conjunto de experimentos de simulação para avaliar o efeito das composições ótimas propostas para a arrecadação desse conjunto de tributos e comparar seus perfis de crescimento com o crescimento da arrecadação realizada 
com as participações praticadas pelo governo nesse mesmo conjunto de tributos. Ou seja, para um determinado conjunto de tributos, computamos diversas carteiras ótimas com o modelo de seleção de carteiras da seção 2.2 e as comparamos com as carteiras praticadas pelo governo.

Nesses experimentos, que serão apresentados mais adiante na seção 4, nós utilizamos os métodos que descreveremos a seguir para selecionar carteiras ótimas de tributos formadas a partir de suas séries históricas de crescimento de receita e simular seus desempenhos em termos de crescimento de arrecadação. As carteiras de tributos vigentes em cada ano de nosso horizonte de simulação foram selecionadas ao final do ano anterior, utilizando apenas os dados históricos disponíveis para o conjunto de tributos até aquele instante - portanto, sem conhecimento prévio de dados nos tempos posteriores, e seus crescimentos mensais ao longo do respectivo ano foram contabilizados. Esse procedimento foi repetido para os quatro anos do horizonte de simulação, 2006-09, e ao final deste período nós comparamos os históricos dos desempenhos das carteiras ótimas propostas com os desempenhos das carteiras praticadas pelo governo no mesmo conjunto de tributos e também com o desempenho do agregado da arrecadação federal.

Esta seção descreve os métodos utilizados na consecução de nossos experimentos, apresentando as séries de receitas de tributos e agregados tributários utilizadas, os períodos utilizados para a estimação dos parâmetros dos modelos e para as simulações de desempenho, e as métricas de avaliação empregadas.

\subsection{Receitas utilizadas e abordagem por macrocarteiras}

Nossas análises foram baseadas no demonstrativo "Análise da arrecadação das receitas federais", produzido pela Coordenação-Geral de Estudos, Previsão e Análise (Coget) da Secretaria da Receita Federal do Brasil (RFB) e integrante da divulgação dos resultados da arrecadação federal.

$\mathrm{O}$ alvo de nossa análise foi o conjunto de tributos denominado Receitas Administradas pela RFB, conforme divulgado no referido demonstrativo Coget/RFB. Contudo, por motivos metodológicos e de disponibilidade de dados, especialmente de observações suficientes nas séries históricas de longo prazo, foram necessários alguns ajustes nas receitas integrantes do referido conjunto. Em termos efetivos de volume de arrecadação, o conjunto ajustado de receitas utilizado correspondeu aproximadamente ao total das Receitas Administradas pela RFB, descontadas as Receitas Previdenciárias. Nossos métodos e experimentos consideraram adequadamente essa aproximação de forma a não prejudicar as análises e os resultados obtidos no escopo deste estudo.

Entre as diversas receitas integrantes do grupo das Receitas Administradas pela RFB, escolhemos aquelas que seriam mais apropriadas para utilização como instrumento de planejamento e cujas séries históricas estavam disponíveis no banco de dados "Índices analíticos macroeconômicos - receitas públicas", divulgado pelo Instituto de Pesquisa Econômica 
Aplicada (Ipea, 2009), e continham observações suficientes para nossas análises. ${ }^{6}$ A tabela 1 mostra os tributos utilizados neste estudo.

Tabela 1

Tributos integrantes das receitas administradas pela RFB utilizados nas simulações

\begin{tabular}{|ll|}
\hline Sigla & Tributo \\
\hline II & Imposto sobre a Importação \\
IRI & Imposto sobre Produtos Industrializados \\
IOF & Imposto sobre a Renda e Proventos \\
ITR & Imposto sobre Operações de Crédito, Câmbio e Seguro, e sobre Operações relativas a Títulos e Valores Mobiliários \\
Cofins & Contribuição para Financiamento da Seguridade Social \\
PIS/Pasep & Contribuição para o Programa de Integração Social/Programa de Formação do Patrimônio do Servidor Público \\
CSLL & Contribuição Social sobre o Lucro Líquido \\
\hline
\end{tabular}

Este artigo aplica o modelo média-variância na otimização de carteiras de tributos da arrecadação federal. Devido a sua modelagem normal multivariada, o modelo média-variância requer séries históricas com grande número de observações para que suas fronteiras eficientes produzidas não sejam errôneas, fenômeno que acontece quando o número de observações é da ordem do número de ativos (Welsch e Zhou, 2007). Junto a isso, diversas mudanças estruturais ocorridas na economia brasileira e na arrecadação federal somente foram estabilizadas a partir de 1996, de forma que o número insuficiente de observações anuais disponíveis no período estudado — apenas 14 observações anuais entre 1996 e 2009 — impôs a nossas análises a utilização de séries mensais em vez de séries anuais.

A principal consequência da utilização de séries históricas mensais decorre do comportamento das séries de tributos que, devido a sua forma de arrecadação, têm suas receitas concentradas em determinados meses do ano - tributos com fato gerador continuado ou com fato gerador complexivo, como o ITR e o IR, respectivamente (Borba, 2007:98-99). Essa característica dessas séries históricas mensais deturpa fortemente suas médias e variâncias, prejudicando a utilização dessas medidas como valor esperado do crescimento da arrecadação mensal e da instabilidade associada. Optamos por contornar esse problema, dentro do escopo deste estudo, através da agregação dos tributos da tabela 1 (e suas respectivas séries histó-

\footnotetext{
${ }^{6}$ As receitas integrantes da rubrica Receita Administrada pela RFB da tabela "Arrecadação das receitas federais" divulgada pela Coget/RFB que não foram consideradas são: imposto sobre exportação; CPMF — Contrib. Movimentação Financeira; Cide-combustíveis; pagamento unificado; contribuição para o Fundaf; outras receitas administradas; Refis; retenção na fonte — Lei no 10.833 , art. 30; e receita previdenciária.
} 
ricas) na forma da organização do título 3 do CTN, adicionadas as contribuições (ver seção 2.1). A tabela 2 mostra os agregados tributários utilizados em nossas análises, os quais denominamos "agregados CTN", bem como suas composições relativas aos tributos da tabela 1.

Tabela 2

Conjunto de agregados do Código Tributário Nacional utilizado nas simulações

\begin{tabular}{|lll|}
\hline Sigla & Agregado tributário & Composição \\
\hline TProdcirc & Produção e circulação & IPI + IOF \\
TComex & Comércio exterior & II \\
TContrib & Contribuiç̃̃es & Cofins + CSLL + Pis/Pasep \\
TProprenda & Propriedade e renda & ITR + IR \\
TRecadm & Agregado CTN Total & TProdcirc + TComex + TContrib + TProprenda \\
\hline
\end{tabular}

Dessa forma, empregamos uma abordagem de macrocarteiras para a diversificação da arrecadação, conforme descrito na seção 2.2.2. Os macroativos são constituídos pelos agregados TProdcirc, TComex, TContrib e TProprenda, e a carteira resultante é denominada "macrocarteira de tributos". A otimização das macrocarteiras de tributos é tratada pelo modelo média-variância da mesma forma descrita na seção 2.2 para o caso das carteiras de tributos, a partir do cálculo das medidas de crescimento esperado e instabilidade para cada agregado CTN.

A receita total do agregado TRecadm reflete a arrecadação federal do conjunto de tributos da tabela 1 (agregados conforme a tabela 2), e sua composição, em termos das participações das receitas dos agregados TProdcirc, TComex, TContrib e TProprenda, reflete a macrocarteira praticada pelo governo federal, que é resultante das políticas fiscais vigentes em cada ano do período de nossas análises.

\subsection{Estratégia de simulação}

O modelo média-variância pertence a uma classe de estratégias denominada "abordagens de período único", ou "modelos estáticos". Estes modelos otimizam carteiras para apenas um período de tempo, usando os dados históricos disponíveis e seus valores esperados e riscos ex ante para o próximo período de tempo (Sharpe, Alexander e Bailey, 1999:139).7

A estratégia de simulação utilizada incluiu o rebalanceamento anual das carteiras de tributos, com a finalidade de aproximar as simulações da situação real do processo orçamentário brasileiro, regido pela elaboração anual da Lei das Diretrizes Orçamentárias (LDO) e

\footnotetext{
${ }^{7}$ Para uma discussão adicional desse assunto, ver Elton et al. (2007:90-92).
} 
da Lei Orçamentária Anual (LOA). Como utilizamos séries mensais de receitas (ver seção 3.3 adiante), a estratégia clássica implementada pelos modelos estáticos de seleção de carteiras foi aqui adaptada para:

1. ao término do mês de dezembro de cada ano, calcular a fronteira eficiente para a seleção da carteira que irá vigorar no próximo ano, a partir dos dados disponíveis até o momento; ${ }^{8}$

2. selecionar a carteira desejada na fronteira eficiente a partir dos critérios de crescimento esperado e instabilidade associada;

3. contabilizar os crescimentos mensais da carteira selecionada durante seu ano de vigência;

4. obter a carteira que irá vigorar no ano seguinte segundo esse mesmo procedimento.

Na aplicação clássica do modelo média-variância no mercado de ações, a estratégia dos modelos estáticos leva em consideração algumas premissas subjacentes (Fischer e Jordan, 1995; Elton et al., 2007; Sharpe, Alexander e Bailey, 1999), que foram aqui adaptadas para o problema da diversificação da arrecadação como:

、 as participações selecionadas de cada tributo são implementáveis;

v todos os dados necessários aos cálculos das fronteiras eficientes estão disponíveis quando da sua obtenção;

as receitas dos tributos têm elasticidade suficiente para responder às participações selecionadas.

\subsection{Dados}

Nosso conjunto fundamental de dados foi formado pelas oito séries históricas dos tributos da tabela 1, com 161 observações mensais cada uma, entre janeiro de 1996 e maio de 2009. A partir dessas séries históricas, obtivemos as cinco séries históricas dos agregados CTN da tabela 2, com os mesmos números de observações mensais e datas, calculando a receita de cada agregado CTN conforme sua composição descrita na tabela.

Implementamos a estratégia da seção 3.2 para formar as macrocarteiras de tributos e simular seus desempenhos durante os 41 meses entre janeiro de 2006 e maio de 2009. As macrocarteiras para o ano de 2006 foram formadas em dezembro de 2005 a partir de séries históricas com 120 observações entre janeiro de 1996 e dezembro de 2005. Ao término do

\footnotetext{
${ }^{8} \mathrm{O}$ art. 35, § 2º, inciso III, da CF/88 estipula que o projeto de lei orçamentária da União será encaminhado até quatro meses antes do encerramento do exercício financeiro, e a formação das carteiras no mês de dezembro não atende a essa restrição constitucional. Contudo, essa opção se deu por aspectos metodológicos e não prejudicou as análises e os resultados obtidos no escopo deste estudo.
} 
ano de 2006, as macrocarteiras foram rebalanceadas para o ano de 2007, sendo formadas em dezembro de 2006 a partir de séries históricas com 120 observações entre janeiro de 1997 e dezembro de 2006. As macrocarteiras para os demais anos foram obtidas da mesma forma, sendo rebalanceadas sempre a partir das fronteiras eficientes calculadas com séries históricas contendo 120 observações mensais e com a última observação referente a dezembro do ano anterior ao ano de sua vigência. O conjunto das macrocarteiras obtidas foi acompanhado durante os 41 meses do período de simulação, entre janeiro de 2006 e maio de 2007, e suas taxas de crescimento mensal foram calculadas conforme a eq. 1.

As séries históricas das receitas dos tributos da tabela 1 foram obtidas diretamente do sítio eletrônico do Ipea (2009) e utilizadas para calcular as séries históricas das receitas dos agregados CTN da tabela 2.

\subsection{Métricas}

As métricas de avaliação do desempenho das macrocarteiras de tributos e dos agregados totais da arrecadação federal são descritas nesta seção. As avaliações de desempenho das macrocarteiras de tributos utilizadas nos experimentos da seção 4 foram baseadas nas medidas de crescimento médio, instabilidade e crescimento acumulado da arrecadação das macrocarteiras de tributos, apresentadas a seguir.

De forma similar à eq. 1, o crescimento da arrecadação da macrocarteira de tributos é definido como:

$$
g_{A t}=\frac{A_{t}-A_{t-1}}{A_{t-1}}, \quad t \geq 1
$$

onde $g_{A t}$ é o crescimento de um período da arrecadação da macrocarteira de tributos no tempo $t$, e $A_{t}$ e $A_{t-1}$ são suas arrecadações nos tempos $t$ e $t_{t-1}$, respectivamente.

O crescimento médio da arrecadação da macrocarteira de tributos no período de interesse, por sua vez, é definido como:

$$
\bar{g}_{A}=\frac{1}{n} \sum_{t=1}^{n} g_{A t}
$$

onde $\bar{g}_{A}$ é o crescimento médio da arrecadação da macrocarteira de tributos, $n$ é o número de observações no período de interesse e $g_{A t}$ é o crescimento da arrecadação da macrocarteira de tributos em cada tempo $t$ do período de interesse.

A instabilidade associada ao crescimento médio da arrecadação (eq. 17) é dada pela variância dos crescimentos da arrecadação no período de interesse, definida como: 


$$
v_{A}=\sigma_{A}^{2}=\frac{1}{n-1} \sum_{t=1}^{n}\left(g_{A t}-\bar{g}_{A}\right)^{2}
$$

onde $v_{A}$ é a instabilidade associada ao crescimento médio da arrecadação da macrocarteira de tributos, $n$ é o número de observações no período de interesse, $g_{A t}$ é o crescimento realizado da arrecadação no tempo $t$ e $\bar{g}_{A}$ é seu crescimento médio no período de interesse.

O crescimento acumulado da arrecadação no período de interesse, $C_{A}$, é aqui definido como:

$$
c_{A}=\prod_{t=1}^{n}\left(1+g_{A t}\right)
$$

onde $C_{A}$ é o crescimento acumulado da arrecadação no período de interesse, $n$ é o número de observações no período e $g_{A t}$ são os crescimentos da arrecadação em cada tempo. O crescimento acumulado relaciona o valor da arrecadação da macrocarteira de tributos (nível de preços) no tempo $t, A_{t}$, com seu valor no tempo $t=1, A_{1}$, como:

$$
A_{t}=A_{1} c_{A t}
$$

Todas as análises envolvendo o crescimento acumulado da arrecadação que foram realizadas neste estudo utilizaram uma arrecadação inicial $A_{1}=\$ 1$ (uma unidade monetária), e o crescimento acumulado alcançado representa o fator multiplicativo da arrecadação inicial obtido com a estratégia utilizada.

Essas mesmas métricas foram aplicadas nas análises do agregado total da arrecadação e do total das Receitas Administradas pela RFB.

\section{Experimentos}

Avaliamos o efeito das composições ótimas propostas para a arrecadação das receitas de um conjunto de agregados tributários, os agregados CTN da tabela 2 (ver seção 3.1), e comparamos seus perfis de crescimento com as composições praticadas pelo governo federal nesse mesmo conjunto de agregados tributários, e também com o crescimento da arrecadação federal, durante os anos de 2006 e 2009. Esta seção mostra os resultados experimentais obtidos nessa investigação, que foi conduzida com os modelos apresentados na seção 2 e os métodos na seção 3. 


\subsection{Cenários avaliados}

Nossas simulações e avaliações foram realizadas para três cenários de instabilidade (risco) do crescimento da arrecadação: (a) conservador; (b) moderado; e (c) agressivo. Devido à geometria das fronteiras eficientes, esses cenários de instabilidade do crescimento mantêm correspondência com cenários equivalentes de crescimento esperado. Dessa forma, implementamos a estratégia de simulação da seção 3.2 selecionando macrocarteiras de tributos de baixo crescimento esperado (cenário conservador), de crescimento esperado moderado (cenário moderado) e de alto crescimento esperado (cenário agressivo), conforme os critérios da tabela 3, correspondendo aos crescimentos mensais esperados de $1,5 \%, 2,5 \%$ e $3,5 \%$, respectivamente.

Tabela 3

Critérios de seleção das macrocarteiras de tributos

\begin{tabular}{|ll|}
\hline Cenário & Crescimento mensal esperado \\
\hline Conservador & $1,5 \%$ \\
Moderado & $2,5 \%$ \\
Agressivo & $3,5 \%$ \\
\hline
\end{tabular}

Nesse conjunto de análises, empregamos o modelo média-variância para diversificação da arrecadação (seção 2.2.2) aos agregados CTN da tabela 2 (seção 3.1), restringindo a participação do agregado TComex (comércio exterior) a seus valores históricos no período investigado, que variaram entre 3,03\% e 3,73\%, através da fixação de seus limites de participação na eq. 15 nesses valores, respectivamente para os limites inferior $\left(l_{i}\right)$ e superior $\left(u_{i}\right)$. Esta delimitação teve o objetivo de avaliar apenas cenários que preservassem as políticas de comércio exterior vigentes. Os demais agregados CTN da tabela 2 não contaram com restrições adicionais de participação.

\subsection{Fronteiras eficientes obtidas}

Calculamos fronteiras eficientes de instabilidade-crescimento formadas com 10 macrocarteiras. As fronteiras foram obtidas por meio da parametrização do crescimento de arrecadação desejado (eq. 12), em 10 valores distintos localizados na região de factibilidade dos modelos, conforme indicado por Elton e colaboradores (2007).

As quatro fronteiras eficientes obtidas - uma para cada ano do período de simulação 2006-09 - são mostradas na figura 3. Conforme a figura, as fronteiras eficientes apresentaram crescimentos mensais esperados no intervalo de $1,5 \%$ a $4,5 \%$, com uma instabilidade associada (variância do crescimento) ao intervalo de 0,0045 a 0,065, aproximadamente. 


\section{Figura 3}

\section{Fronteiras eficientes de instabilidade-crescimento obtidas para as macrocarteiras de tributos}

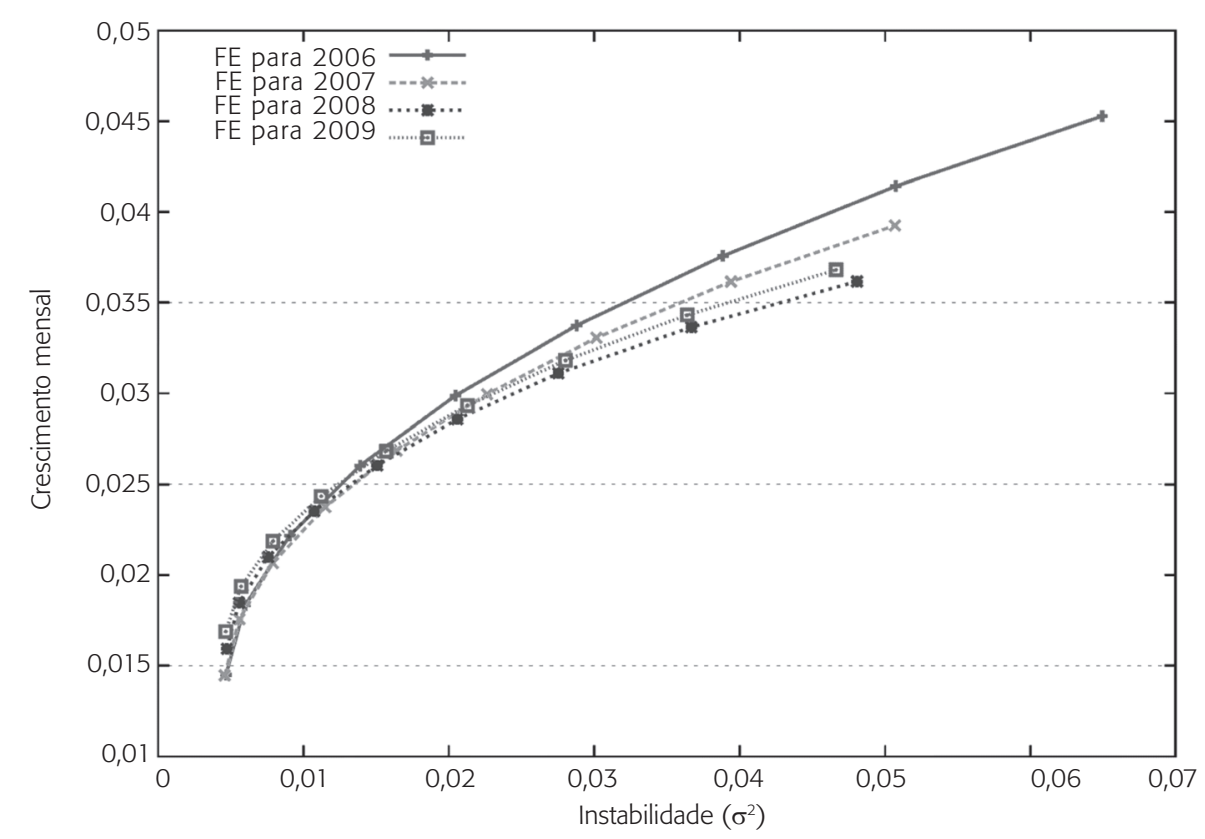

\subsection{Desempenho das macrocarteiras de tributos}

Para cada ano do período de simulação, 2006-09, aplicamos os critérios de seleção da tabela 3 às fronteiras eficientes da seção 4.2 e selecionamos as macrocarteiras de tributos conservador, moderado e agressivo, respectivamente, para os níveis de crescimento de arrecadação mensal desejado (eq. 12), de 1,5\%, 2,5\% e 3,5\%. As macrocarteiras de tributos do Agregado CTN Total — CTRecadm - foram formadas anualmente entre 2006 e 2009 pelas participações da receita de cada agregado CTN na receita do Agregado CTN Total - TRecadm — (tabela 2), e refletiram a composição ex post da arrecadação federal realizada pelo governo no agregado TRecadm em cada ano do período de simulação. Os crescimentos mensais e instabilidades de todas essas macrocarteiras foram calculados entre janeiro de 2006 e maio de 2009 e avaliados em nossos experimentos.

Avaliamos a alocação das participações dos agregados CTN nas macrocarteiras de tributos CTRecadm, conservador, moderado e agressivo, juntamente com os crescimentos médios mensais (eq. 17), as instabilidades (eq. 18) e os crescimentos acumulados (eq. 19) das macrocarteiras. Também avaliamos os crescimentos médios mensais, as instabilidades e os 
crescimentos acumulados totais no período de todas as macrocarteiras de tributos e também da arrecadação das Receitas Administradas pela RFB (Recadm). ${ }^{9}$

A tabela 4 mostra os resultados obtidos e está organizada em cinco partes, conforme a seguir. Nas quatro primeiras partes da tabela, as linhas apresentam os resultados das quatro macrocarteiras agrupados para cada ano do período de simulação (2006-09). Para cada macrocarteira, as participações de cada agregado CTN são mostradas nas colunas TProdcirc, TComex, TContrib e TProprenda. O desempenho do crescimento das macrocarteiras é mostrado nas colunas Crescimento médio, Instabilidade e Crescimento acumulado. A última parte da tabela 4 mostra o desempenho do crescimento das macrocarteiras e da arrecadação federal, este último dado pelo conjunto das Receitas Administradas pela RFB (Recadm), para o período total 2006-09. Nessa parte da tabela, as linhas apresentam os resultados do crescimento do agregado Recadm e das macrocarteiras CTRecadm, conservador, moderado e agressivo; e as colunas Crescimento médio, Instabilidade e Crescimento acumulado apresentam os respectivos desempenhos alcançados.

Tabela 4

Composição e desempenho das macrocarteiras de tributos e da arrecadação das Receitas Administradas pela RFB

\begin{tabular}{|c|c|c|c|c|c|c|c|}
\hline Macrocarteira & TProdcirc & TComex & TContrib & TProprenda & $\begin{array}{c}\text { Crescimento } \\
\text { médio }\end{array}$ & Instabilidade & $\begin{array}{c}\text { Crescimento } \\
\text { acumulado }\end{array}$ \\
\hline \multicolumn{8}{|c|}{ Ano base 2005 para vigência em 2006} \\
\hline CTRecadm & $10,79 \%$ & $3,03 \%$ & $45,23 \%$ & $40,96 \%$ & $1,28 \%$ & 0,022 & $3,77 \%$ \\
\hline Conservador & $64,22 \%$ & $3,73 \%$ & $31,37 \%$ & $0,67 \%$ & $0,83 \%$ & 0,0048 & $5,00 \%$ \\
\hline Moderado & $34,45 \%$ & $3,73 \%$ & $30,81 \%$ & $31,01 \%$ & $1,93 \%$ & 0,016 & $4,52 \%$ \\
\hline Agressivo & $14,60 \%$ & $3,73 \%$ & $30,43 \%$ & $51,24 \%$ & $2,67 \%$ & 0,032 & $4,20 \%$ \\
\hline \multicolumn{8}{|c|}{ Ano base 2006 para vigência em 2007} \\
\hline CTRecadm & $10,78 \%$ & $3,11 \%$ & $44,28 \%$ & $41,83 \%$ & $2,54 \%$ & 0,016 & $24,52 \%$ \\
\hline Conservador & $61,67 \%$ & $3,73 \%$ & $33,03 \%$ & $1,57 \%$ & $2,83 \%$ & 0,0051 & $33,00 \%$ \\
\hline Moderado & $30,38 \%$ & $3,73 \%$ & $35,45 \%$ & $30,43 \%$ & $2,98 \%$ & 0,011 & $27,91 \%$ \\
\hline Agressivo & $0,00 \%$ & $3,73 \%$ & $23,06 \%$ & $73,21 \%$ & $3,25 \%$ & 0,028 & $21,23 \%$ \\
\hline \multicolumn{8}{|c|}{ Ano base 2007 para vigência em 2008} \\
\hline CTRecadm & $11,01 \%$ & $3,25 \%$ & $43,48 \%$ & $42,26 \%$ & $0,71 \%$ & 0,020 & $-3,09 \%$ \\
\hline Conservador & $63,02 \%$ & $3,73 \%$ & $33,25 \%$ & $0,00 \%$ & $0,68 \%$ & 0,0024 & $4,20 \%$ \\
\hline Moderado & $14,86 \%$ & $3,73 \%$ & $45,77 \%$ & $35,64 \%$ & $1,13 \%$ & 0,017 & $-2,03 \%$ \\
\hline Agressivo & $0,00 \%$ & $3,03 \%$ & $10,50 \%$ & $86,47 \%$ & $1,87 \%$ & 0,045 & $-6,06 \%$ \\
\hline
\end{tabular}

${ }^{9}$ A série histórica das Receitas Administradas pela RFB (Recadm) foi obtida no sítio eletrônico do Ipea (2009). 


\begin{tabular}{|c|c|c|c|c|c|c|c|}
\hline Macrocarteira & TProdcirc & TComex & TContrib & TProprenda & $\begin{array}{l}\text { Crescimento } \\
\text { médio }\end{array}$ & Instabilidade & $\begin{array}{l}\text { Crescimento } \\
\text { acumulado }\end{array}$ \\
\hline \multicolumn{8}{|c|}{ Ano base 2008 para vigência em 2009* } \\
\hline CTRecadm & $12,94 \%$ & $3,71 \%$ & $42,22 \%$ & $41,13 \%$ & $-2,57 \%$ & 0,051 & $-21,79 \%$ \\
\hline Conservador & $59,41 \%$ & $3,73 \%$ & $35,82 \%$ & $1,04 \%$ & $-3,75 \%$ & 0,011 & $-20,61 \%$ \\
\hline Moderado & $28,47 \%$ & $3,73 \%$ & $37,57 \%$ & $30,23 \%$ & $-2,60 \%$ & 0,032 & $-21,23 \%$ \\
\hline Agressivo & $0,00 \%$ & $3,73 \%$ & $22,66 \%$ & $73,61 \%$ & $-1,82 \%$ & 0,083 & $-25,69 \%$ \\
\hline \multicolumn{8}{|c|}{ Período 2006-09* } \\
\hline Recadm & & & & & $0,77 \%$ & 0,019 & $-7,56 \%$ \\
\hline CTRecadm & & & & & $1,01 \%$ & 0,021 & $-2,06 \%$ \\
\hline Conservador & & & & & $0,81 \%$ & 0,0048 & $26,51 \%$ \\
\hline Moderado & & & & & $1,45 \%$ & 0,016 & $31,46 \%$ \\
\hline Agressivo & & & & & $2,06 \%$ & 0,038 & $7,16 \%$ \\
\hline
\end{tabular}

* Até maio 2009.

Conforme mostrado na primeira parte da tabela 4, a composição tributária da arrecadação realizada (macrocarteira CTRecadm) apresentou pouca variação no período 2006-09, distribuindo-se basicamente entre os agregados TContrib (42,22\% a 45,23\%) e TProprenda (40,96\% a 42,26\%).

A macrocarteira conservador também ficou praticamente estável no período 200609, concentrando-se fortemente no agregado TProdcirc $(59,41 \%$ a $64,22 \%)$ e no agregado TContrib (31,37\% a 35,82\%). A macrocarteira moderado, por sua vez, apesar de distribuir suas participações de forma mais equânime no período, apresentou um comportamento mais ativo, buscando crescimento através de uma maior alternância de participações entre os agregados TProdcirc (14,86\% a 34,45\%), TContrib (30,81\% a 45,77\%) e TProprenda $(30,23 \%$ a $35,64 \%)$. Por fim, a macrocarteira agressivo salientou o comportamento ativo na busca de crescimento adicional, contudo, concentrou-se apenas nos agregados TContrib $(10,50 \%$ a $30,43 \%)$ e TProprenda $(73,21 \%$ a $86,47 \%)$. Vale lembrar que o agregado TComex foi restrito à sua participação histórica de 3,03\% a 3,73\%, conforme descrito anteriormente.

Em todos os anos, a macrocarteira conservador apresentou um crescimento acumulado maior do que aquele da macrocarteira CTRecadm praticada pelo governo, exibindo uma instabilidade (risco) três a oito vezes menor (ver as colunas Crescimento acumulado e Instabilidade nas quatro primeiras partes da tabela 4). A macrocarteira conservador superou o crescimento acumulado da macrocarteira CTRecadm em 8,48 pontos percentuais em 2007 - ano de forte crescimento da economia mundial - e em 7,29 pontos percentuais em 2008 - ano que a CTRecadm fechou em queda de 3,09\%. Durante os primeiros cinco 
meses de 2009, período de quedas acentuadas e repetidas da arrecadação federal devido aos efeitos do agravamento da crise internacional deflagrada em outubro de 2008, o crescimento acumulado da macrocarteira conservador superou o da macrocarteira CTRecadm em 1,18 ponto percentual.

A macrocarteira moderado apresentou níveis de risco próximos aos da macrocarteira CTRecadm para a maioria dos anos, com crescimento acumulado superior em 0,75 ponto percentual para 2006, em 3,39 pontos percentuais para 2007 , em 1,06 ponto percentual para 2008, e fechando os cinco primeiros meses de 2009 com 0,56 ponto percentual acima.

A macrocarteira agressivo apresentou níveis de risco maiores que os da macrocarteira CTRecadm e crescimento acumulado inferior, exceto em 2006 quando seu crescimento foi 0,43 ponto percentual acima. Isso se deve a suas escolhas por participações maiores em agregados com maior crescimento esperado e, consequentemente, com maior instabilidade associada.

Os resultados para o período 2006-09 (última parte da tabela 4) mostraram que as macrocarteiras conservador alcançaram um crescimento acumulado 28,57 pontos percentuais acima das macrocarteiras CTRecadm praticadas pelo governo e 34,07 pontos percentuais acima das Receitas Administradas pela RFB (Recadm), com apenas um quarto da instabilidade exibida pela CTRecadm e pela Recadm.

As macrocarteiras moderado alcançaram um crescimento acumulado total ainda maior, atingindo 33,52 pontos percentuais acima das macrocarteiras CTRecadm e 39,02 pontos percentuais acima das Receitas Administradas pela RFB (Recadm), exibindo uma instabilidade ligeiramente inferior à instabilidade da CTRecadm e da Recadm.

Por fim, as macrocarteiras agressivo alcançaram um crescimento acumulado total 9,22 pontos percentuais acima das macrocarteiras CTRecadm e 14,72 pontos percentuais acima das Receitas Administradas pela RFB (Recadm), com instabilidade superior à instabilidade da CTRecadm e da Recadm.

Vale notar que, mesmo apresentando um crescimento médio inferior, as macrocarteiras conservador alcançaram um crescimento acumulado total bastante superior ao das macrocarteiras CTRecadm praticadas pelo governo no período 2006-09. Isso pode ser explicado pela instabilidade quatro vezes menor exibida pelas macrocarteiras conservador no período, e demonstra claramente o efeito prejudicial que a instabilidade da arrecadação exerce em seu crescimento no médio e no longo prazo. 
Figura 4

Crescimento acumulado das macrocarteiras de tributos e da arrecadação das Receitas Administradas pela RFB

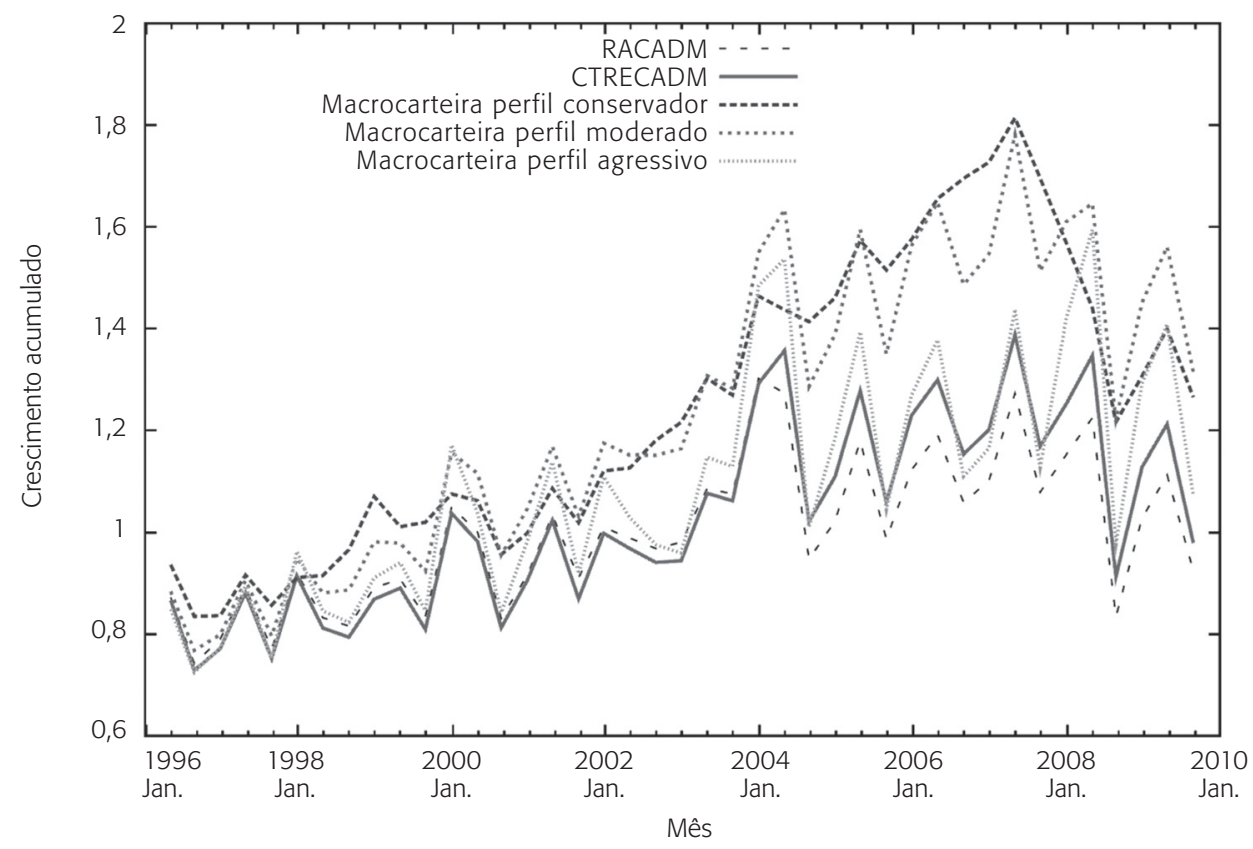

\section{Discussão}

Neste artigo, estudamos a aplicação de ferramentas da moderna teoria de finanças na gestão da arrecadação de tributos, conforme proposto por Thompson e Gates (2007), empregando o modelo média-variância na diversificação ótima da arrecadação federal brasileira segundo a linha de investigação estudada por Gentry e Ladd (1994).

Gentry e Ladd minimizaram a instabilidade de carteiras de tributos de dois estados dos EUA, incorporando restrições de progressividade e de competitividade em seu modelo. Nosso estudo, por sua vez, tratou da arrecadação federal brasileira, otimizando macrocarteiras de tributos que preservassem as políticas de comércio exterior vigentes, restringindo as participações do agregado comércio exterior (TComex) àquelas praticadas pelo governo federal no período de simulação. Preservando as diferenças entre esses dois estudos em termos de comparabilidade, encontramos perfis bastante distintos de participações dos agregados tributários incidentes sobre a renda e sobre as vendas para o caso brasileiro em relação ao trabalho de Gentry e Ladd. Enquanto eles encontraram uma dominância do imposto sobre a renda nas carteiras ótimas para uma grande faixa de crescimentos esperados da fronteira eficiente, 
nossas participações encontradas para o agregado propriedade e renda (TProprenda) foram crescentes ao longo da faixa de crescimentos esperados, sendo dominantes apenas para os maiores crescimentos esperados; e enquanto eles encontraram participações da tributação sobre as vendas crescentes ao longo da faixa de crescimentos esperados, nós encontramos participações decrescentes para o agregado produção e circulação (TProdcirc) ao longo da faixa de crescimentos esperados em nossas fronteiras eficientes.

O ponto focal da investigação de nosso estudo é a obtenção de participações ótimas de agregados tributários na arrecadação federal, de forma que sua instabilidade possa ser minimizada para um determinado nível de crescimento desejado. Essas participações são apresentadas como aquelas das macrocarteiras de tributos da tabela 4 e devem ser adequadamente interpretadas em relação às participações dos agregados tributários no agregado total da arrecadação federal - no caso de nossos experimentos da seção 4, as participações dos agregados do Código Tributário Nacional (agregados CTN) na macrocarteira de tributos do Agregado CTN Total (CTRecadm).

Dessa forma, tomando como exemplo nossos resultados para 2009, enquanto a macrocarteira CTRecadm praticada pelo governo apresentou participações nos agregados TProdcirc, TComex, TContrib e TProprenda de 12,94\%, 3,71\%, 42,22\% e 41,13\%, respectivamente, a macrocarteira conservador apresentou participações de 59,41\%, 3,73\%, 35,82\% e 1,04\%, respectivamente, para os mesmos agregados. Isto indica que, no contexto analisado neste artigo, a arrecadação federal poderia ser otimizada para o perfil conservador naquele ano através de políticas fiscais que promovessem um ajuste da distribuição da carga tributária de 46,47 pontos percentuais () para o agregado TProdcirc, de 0,02 ponto percentual () para o TComex, de $-6,40$ pontos percentuais () para o TContrib e de $-40,09$ pontos percentuais () para o TProprenda.

Os resultados obtidos nos experimentos da seção 4, e acima ilustrados para o ano de 2009, sugerem forte oneração em produção e circulação (TProdcirc), forte desoneração em propriedade e renda (TProprenda), e desoneração moderada em contribuições (TContrib). Tais mudanças de paradigma tributário podem ser inviáveis na prática, e não se constituem, necessariamente, em propostas acabadas para políticas fiscais anticíclicas no âmbito da arrecadação federal brasileira. Contudo, há que se observar o drástico efeito desses resultados no crescimento e controle da instabilidade da arrecadação, conforme mostrado na tabela 4 e na figura 4. Dessa forma, o modelo média-variância para diversificação da arrecadação da seção 2.2 pode ser aperfeiçoado para aplicações mais realistas de diversas maneiras, como através da utilização de um conjunto adequado de limites para as participações dos agregados CTN nas macrocarteiras (eq. 15), obtidos, por exemplo, com estimativas do tax gap dos agregados tributários, e da inclusão das restrições de progressividade e competitividade propostas por Gentry e Ladd (1994), somente para citar algumas.

O processo legislativo orçamentário brasileiro é definido no art. $35, \S 2^{\circ}$, inciso III, da $\mathrm{CF} / 88$, e estipula que o projeto de lei orçamentária da União será encaminhado até quatro meses antes do encerramento do exercício financeiro. Além disso, os princípios constitucionais tributários implicam um conjunto de regras de anterioridade aplicáveis (art. 150, III, 
CF/88) que retardam a eficácia da alteração de tributos. Dessa forma, a aplicação prática dos arcabouços desenvolvidos neste estudo no planejamento e otimização da arrecadação implica ajustes na metodologia descrita na seção 3 para essa situação. Nesse caso, duas soluções se aplicam: a utilização de métodos de predição para vários períodos (Box, Jenkins e Reinsel, 1994; Morettin e Toloi, 2004; Sutton, 1988) no fornecimento das estimativas de crescimento mensal esperado e instabilidade dos agregados tributários para o ano seguinte ao da elaboração da lei orçamentária, adequando o horizonte de planejamento de nossos métodos a essa situação; e a utilização de métodos para a estimação do crescimento anual esperado e instabilidade dos agregados tributários, visando contornar o problema das séries históricas anuais com poucas observações. Para esse último caso, Silva (1996) propôs a utilização da estimação de valores esperados através de cenários. Contudo, esta alternativa apresenta a tarefa adicional de se estimar a arrecadação anual do ano corrente estando ainda a quatro meses do encerramento de seu exercício.

Por fim, vale ressaltar que a elaboração de políticas fiscais efetivas é uma tarefa de alta complexidade e envolve inúmeros aspectos de interesse da sociedade além daqueles abordados neste artigo, como a distribuição de renda, as políticas setoriais e a preservação de postos de trabalho e massa salarial, somente para citar alguns.

\section{Conclusões e trabalhos futuros}

Neste artigo, empregamos o modelo média-variância de Harry Markowitz na obtenção de macrocarteiras de tributos com composições ótimas das participações de agregados tributários na arrecadação federal. Essas macrocarteiras ótimas, ou "macrocarteiras eficientes", são aquelas que produzem a menor instabilidade da arrecadação para um determinado crescimento esperado, ou um maior crescimento esperado para uma determinada instabilidade aceitável da arrecadação. Desenhamos um conjunto de experimentos de simulação para avaliar o efeito dessas composições ótimas propostas para a arrecadação federal e comparar seus perfis de crescimento com o crescimento da arrecadação realizada.

Nossos resultados experimentais mostraram que, no contexto analisado, a estrutura tributária da arrecadação federal opera em um nível subótimo de instabilidade-crescimento. Através da diversificação eficiente das receitas dos agregados tributários foi possível obter, no perfil conservador, um crescimento acumulado de arrecadação 28 pontos percentuais acima do crescimento acumulado realizado dos mesmos agregados tributários e com apenas $25 \%$ de sua instabilidade - um risco quatro vezes menor. No perfil moderado, foi alcançado um crescimento acumulado 33 pontos percentuais acima, para o mesmo nível de instabilidade.

Nossos trabalhos futuros incluem:

v a investigação de métodos adequados para a estimação do crescimento anual esperado e da instabilidade dos agregados tributários de forma a contornar o problema da falta de observações das séries históricas anuais; 
- a aplicação recursiva do arcabouço desenvolvido em níveis mais baixos de desagregação, através da derivação de técnicas adequadas para o tratamento dos dados desagregados em relação aos problemas relacionados na seção 3.1;

v a utilização de modelos preditivos de forma a capturar os fatores mais recentes da evolução das séries históricas e oferecer estimativas mais precisas para o crescimento esperado e instabilidade das receitas tributárias;

v o refinamento do modelo média-variância para incorporar restrições mais realistas inerentes ao cenário do planejamento da arrecadação;

- o desenvolvimento de uma metodologia de planejamento adequada ao processo legislativo brasileiro, especialmente às questões de temporalidade na elaboração anual da Lei das Diretrizes Orçamentárias (LDO) e Lei Orçamentária Anual (LOA).

\section{Referências}

BORBA, C. Direito tributário III - livro segundo do Código Tributário Nacional: título 1, legislação tributária, e título 2, obrigação tributária. São Paulo: Campus Jurídico, 2007.

BOX, G.E.P.; JENKINS, G.M.; REINSEL, G.C. Time series analysis: forecasting and control. 3. ed. s.l.: Prentice-Hall, 1994.

BRASIL. Constituição da República Federativa do Brasil de 1988: texto constitucional com alterações das Emendas Constitucionais 1/1992 a 53/2006. 1. ed. Brasília: Senado Federal, Subsecretaria de Edições Técnicas, 2007. (Série fontes de referência. Legislação; no 43)

BRITO NETO, C.T. Macrocarteiras de investimento: seleção e composição. In: BRITO, N.R.O. de (Ed.). Gestão de investimentos. São Paulo: Atlas, 1989. p. 105-122.

DE SOUZA, A.F.; FREITAS, F.D. Supercomputer performance with a workstation cluster on dense matrix multiplication. In: IASTED — International Conference on Parallel and Distributed Computing and Systems. Washington DC, USA: s.n., 1995. p. 257-261.

DUMONT, D.M.; RIBEIRO, J.A.; RODRIGUES, L.A. Inteligência pública na era do conhecimento. Rio de Janeiro: Revan, 2006.

ELTON, E.J. et al. Modern portfolio theory and investment analysis. 7. ed. John Wiley \& Sons, 2007.

FISCHER, D.E.; JORDAN, R.J. Security analysis and portfolio management. 6. ed. Prentice-Hall International, 1995.

FOX, W.F. Three characteristics of tax structures have contributed to the current state fiscal crises. State Tax Notes, n. 29, p. 375-383, Aug. 2003.

GENTRY, W.M.; LADD, H.F. State tax structure and multiple policy objectives. National Tax Journal, v. 47, n. 4, p. 747-772, 1994. 
IPEA. Índices analíticos macroeconômicos: receitas públicas. 2009. Disponível em: <www.ipeadata. gov.br>. Acesso em: jul. 2009.

KEYNES, J.M. The general theory of employment, interest and money. London: Macmillan Press, 1936.

KEYNES, J.M. The general theory of employment. The Quarterly Journal of Economics - The MIT Press, v. 51, n. 2, p. 209-223, 1937.

KEYNES, J.M. Teoria geral do emprego, do juro e da moeda. São Paulo: Atlas, 1992.

KONNO, H. Piecewise linear risk functions and portfolio optimization. Journal of Operations Research Society of Japan, n. 33, p. 139-156, 1990.

KONNO, H.; PLISKA, S.; SUZUKI, K. Optimal portfolio with asymptotic criteria. Operations Research, n. 45, p. 187-204, 1993.

KONNO, H.; SHIRAKAWA, H.; YAMAZAKI, H. A mean-absolute deviation-skewness portfolio optimization model. Annals of Operations Research, v. 45, n. 1, p. 205-220, Dec. 1993.

KONNO, H.; SUZUKI, S. A fast algorithm for solving large scale mean-variance models by compact factorization of covariance matrices. Journal of Operations Research Society of Japan, n. 35, p. 93 104, 1992.

KONNO, H.; YAMAZAKI, H. Mean-absolute deviation portfolio optimization model and its applications to Tokyo stock market. Management Science, New York, v. 37, n. 5, p. 519-531, May 1991.

MARKOWITZ, H.M. Portfolio selection. Journal of Finance, New York, v. 7, n. 1, p. 77-91, Mar. 1952.

MARKOWITZ, H.M. Portfolio Selection: Efficient Diversification of Investments. 2. ed. New York: John Willey \& Sons, 1991.

MORETTIN, P.A.; TOLOI, C.M.C. Análise de séries temporais. 1. ed. Edgar Blücher, 2004.

OCAMPO, J.A. Developing countries' anti-cyclical policies in a globalized world. Santiago, Chile, jun. 2002. (Cepal — Serie Informes y estudios especiales, United Nations Publication)

PAULSEN, L. Direito tributário: constituição e código tributário à luz da doutrina e da jurisprudência. 11. ed. Porto Alegre: Livraria do Advogado/Esmafe, 2009.

SHARPE, W.F. A simplified model for portfolio analysis. Management Science, v. 2, n. 9, p. 277-293, 1963.

SHARPE, W.F. A linear programming approximation for the general portfolio selection problem. Journal of Financial and Quantitative Analysis, n. 6, p. 1263-1275, 1971.

SHARPE, W.F. An algorithm for portfolio improvement. In: LAWRENCE, J.B.; GUERARD, J.K.; REEVES, G.D. (Ed.). Advances in mathematical programming and financial planning. JAI Press, 1987. p. $155-170$.

SHARPE, W.F.; ALEXANDER, G.J.; BAILEY, J.V. Investments. 6. ed. Upper Saddle River, New Jersey: Prentice-Hall, 1999. 
SILVA, A.C.D. O modelo de Harry Markowitz aplicado à dívida pública. In: Escola Superior de Administração Fazendária (Esaf). I Prêmio Tesouro Nacional - 1996, Dívida pública. Monografia vencedora. Brasília, 1996.

SUTTON, R.S. Learning to predict by the method of temporal differences. Machine Learning, v. 3, p. 9-44, 1988.

THOMPSON, F.; GATES, B. Betting on the future with a cloudy crystal ball? How financial theory can improve revenue forecasting and budgets in the states. Public Administration Review, v. 67, n. 5, p. 825-836, Sept. 2007.

VASARHELYI, M.A. A utilização de modelos em administração financeira. Revista de Administração de Empresas, São Paulo, v. 16, n. 3, p. 7-13, 1976.

WELSCH, R.E.; ZHOU, X. Application of robust statistics to asset allocation models. REVSTAT — Statistical Journal, v. 5, n. 1, p. 97-114, Mar. 2007.

WONNACOTT, P.; WONNACOTT, R.J. Economia. McGraw-Hill do Brasil, 1982.

Fábio Daros de Freitas é analista tributário da Receita Federal do Brasil. E-mail: freitas@computer. org.

Christóvão Thiago de Brito Neto é auditor fiscal da Receita Federal do Brasil. E-mail: ctdbnt@gmail. com.

Alberto Ferreira de Souza é coordenador do Programa de Pós-graduação em Informática da Universidade Federal do Espírito Santo (PPGI/Ufes). E-mail: alberto@lcad.inf.ufes.br. 